\title{
A Resource for E-Moderators on Fostering Participatory Engagement Within Discussion Boards for Online Students in Higher Education.
} A Practice Report

\author{
Ameena L. Payne \\ Swinburne Online, Australia
}

\begin{abstract}
Through the lens of the Community of Inquiry education experience (Vaughan \& Garrison, 2006), this practice report provides guidance and examples for online instructors to engage students within discussion boards in the digital realm. Five elements will be discussed: embedding multi-media, affiliative humour and storytelling, Socratic questioning, "reframes" and, summarising and "weaving".

Based on the lived experience of one eLearning Advisor, or online instructor/e-moderator, at Swinburne Online, this practice report offers useful strategies to build engaging, sustainable learning conversations within discussion forums that are abundant with collaborative inquiry, dialogue and sharing of personal learning experiences for online students in higher education.
\end{abstract}

Keywords: Student engagement; online learning; e-moderating; multi-media; discussion board; active participation.

\section{Introduction}

The number of fully online students grew from 17.5\% in 2010 to $26 \%$ in 2019 (Department of Education, Skills and Employment, 2020). Yet, positive ratings for engagement are 62\% less for online learners (The Social Research Centre, 2020). Although the number of fully online students continues to increase, commencing online students consistently rate 'engagement' as the lowest aspect of their experience (The Social Research Centre, 2020).

For the purposes of this report, the proxy we use for 'engagement' is active presence and involved participation in the discussion boards. A discussion forum is an information communication tool that can support structured and semi-structured learning. They are asynchronous, interactive spaces for students to digitally connect, academically and socially, with their peers and the e-moderator.

Engagement tends to drop off as the teaching period progresses. A challenge is starting off in a way that develops a culture of sharing and contributing on the discussion forums and then using facilitation and presence to maintain the best possible levels of discussion board engagement throughout the teaching period.

Except where otherwise noted, content in this journal is licensed under a Creative Commons Attribution 4.0 International Licence. As an open access journal, articles are free to use with proper attribution. ISSN: 2205-0795 


\section{Developing and Maintaining Presence}

Five strategies are suggested: deliberate use of media, affiliative humour and storytelling, Socratic questioning, "reframes" and "weaving" within discussion forums to demonstrate and encourage cooperation, interaction and support.

These aspects relate to a cornerstone of our work as e-moderators, online instructors and facilitators. Our work involves maintaining presence and will be viewed through the lens of the Community of Inquiry framework (CoI) (Vaughan \& Garrison, 2006). The concept of presence in online teaching builds on the body of work of John Dewey, Arthur W. Chickering, Zelda F. Gamson, and many others studying the psychological and sociological aspects of teaching, learning and computer mediated communication.

\section{Three Types of Presence}

A key element of an e-moderator's work is about maintaining three types of presence in learning from the Community of Inquiry (CoI) framework; these types of presence consist of cognitive presence, social presence and teaching presence (Vaughan \& Garrison, 2006) and displayed in Figure 1.

\section{Figure 1}

Community of Inquiry Framework

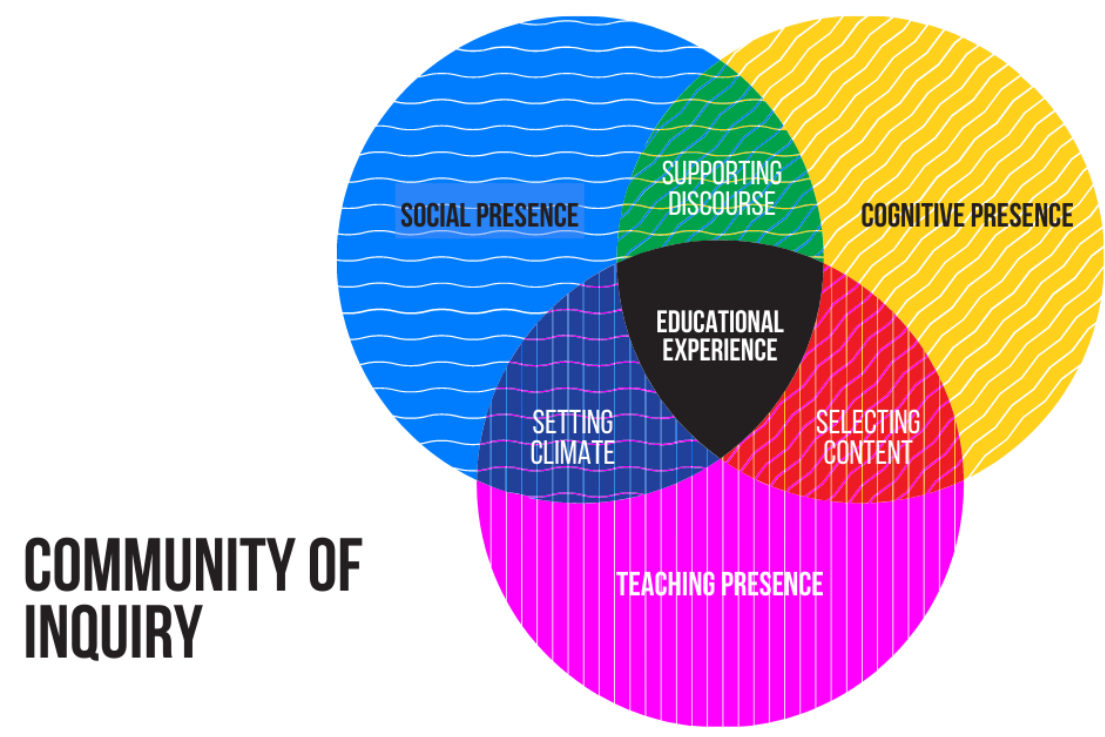

The above illustration shows how the types of presence overlap to provide a balanced and optimised educational experience. I find these categories particularly useful if things are quiet in the discussion boards, to brainstorm ideas for meaningful posts that add value to the student experience.

\section{Cognitive Presence}

Reflecting "high-order knowledge acquisition and application", cognitive presence is most associated with critical thinking (Garrison et al., 2001, p. 6). The attainment of deep, meaningful learning through cognitive presence has been described as follows: 
What is achieved with cognitive presence is an understanding on an intellectual level and on an affective level that the learning activities involve and tap into existing real meaning structures. Integrating existing learning with new learning requires knowledge, reflection, discussion and confirming of meaning. (Boettcher, 2007)

\section{Social Presence}

Social presence is the ability to present oneself as authentic within interpersonal interactions. It is demonstrated by "communication behaviours that enhance closeness to and nonverbal interaction with another" (Mehrabian, 1969, p. 203 as cited in Rourke et al., 2001, p. 3). We can facilitate social presence by encouraging students to upload profile pictures, create virtual study groups and engage in informal conversation.

\section{Teaching Presence}

Anderson et al. (2001) define teaching presence as the design, facilitation and direction of cognitive and social processes for the purposes of realising personally meaningful and educational learning outcomes. Teaching presence can be demonstrated by checking in, collectively congratulating students on their efforts and encouraging discussion contribution.

\section{Strategy \#1 Use media}

Using media meaningfully may pique students' interest and reduces the heavy use of text.

\section{Figure 2}

Use of Media Example

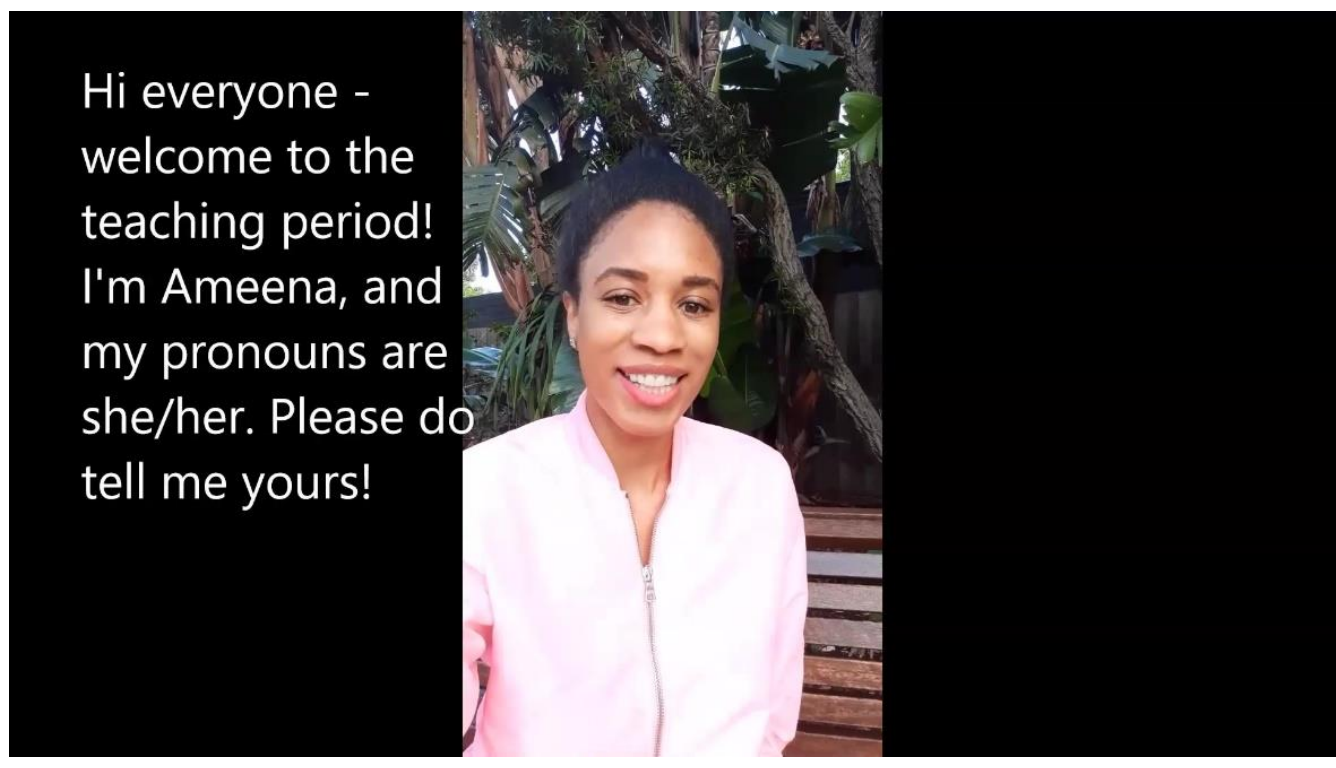

The link to this media example is on Vimeo https://vimeo.com/473597632

There are many tools that can be used to integrate media, a selection of these are: Canva, Powtoon, video or audio recordings, GIPHY and Unsplash. This does not mean that we need to apply a radical shift to using audio/video, memes, emojis, and GIFs as a means of scholarly communication. Instead, we should use multi-media in illustrative and organisational ways to gain students' attention and to add visual appeal. The goal is the modification of instruction and content to generate greater engagement. 
Contrast and colour use are vital to accessibility. Users, including users with visual disabilities, must be able to perceive content on the page. If you are unsure if your text or media meets accessibility requirements, please use the Web Content Accessibility Guidelines (WCAG).

\section{Strategy \#2 Affiliative humour and storytelling}

We all have a unique story to tell. When online instructors incorporate storytelling and "affiliative humour" (Pundt \& Herrmann, 2015), rapport can be more rapidly built. Personal narratives establish human connection which students can more deeply appreciate.

Dialogue is crucial to the student experience. Storytelling should incorporate personal or professional experiences that align to concepts being taught. A personal, engaging and conversational tone initiated by the unit facilitator may assist students in better understanding the content as there is a likelihood that less academic jargon is used.

I like to incorporate such video dialogue as mid-week discussion board prompts; I integrate my own personal/professional experiences with the weekly content. By contextualising the content within my own lived experiences, I strive to demonstrate "teacher immediacy" (Anderson, 1979, p. 544 as cited in Rourke et al., 2001, p. 5). Engaging in eye contact, embracing a relaxed body posture, motioning and smiling improves students' affect toward course content and toward their e-moderator (Rouke et al., 2001). See Figure 3.

\section{Figure 3}

\section{Use of Personal Storytelling Example}

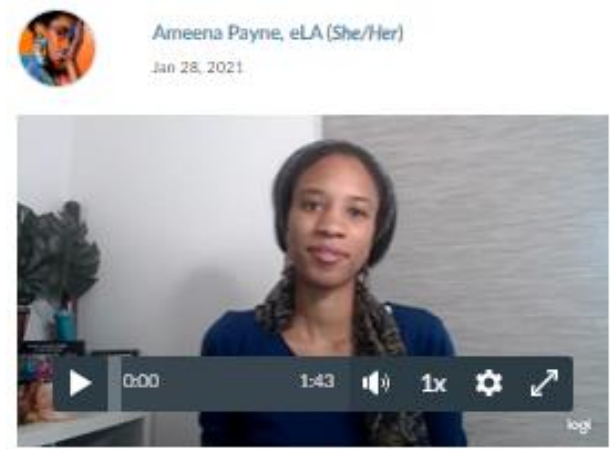

As mentioned in the video, I wanted to share my employability/soft skill development area:

\begin{tabular}{|l|l|l|}
\hline $\begin{array}{l}\text { GOAL } \\
\text { What employability or soft skills do I want to develop } \\
\text { or improve? }\end{array}$ & $\begin{array}{l}\text { CHALLENGES } \\
\text { STRATEGY } \\
\text { What actions can I take? }\end{array}$ & $\begin{array}{l}\text { DATE } \\
\text { When will I } \\
\text { difficulties might I } \\
\text { encounter? }\end{array}$ \\
\hline
\end{tabular}

Teacher immediacy is conceptualised as "nonverbal behaviours that reduce physical and/or psychological distance between teachers and students" (Anderson, 1979, p. 544 as cited in Rourke et al., 2001, p. 5).

\section{Strategy \#3 Socratic questioning}

The Socratic approach to questioning is based on intellectual, introspective dialogue; the early Greek philosopher/teacher, Socrates, believed that thoughtful questioning enabled the student to examine ideas rationally (Payne, 2021).

Socratic questioning encourages student agency and self-regulated learning. Table 1 from Intel (2007) demonstrates how student interactions may be adjusted so that they probe, encourage, empathise and engage. 
Table 1

Socratic Questioning Technique

\begin{tabular}{|c|c|}
\hline Socratic Question Type & Example \\
\hline - $\quad$ Clarification questions & $\begin{array}{l}\text { - } \quad \text { What do you mean by...? } \\
\text { - } \quad \text { Could you put that another way? } \\
\text { - } \quad \text { Could do you think is the main issue? } \\
\text { - Could you expand upon that point further? }\end{array}$ \\
\hline $\begin{array}{l}\text { Questions about an initial } \\
\text { question or issue }\end{array}$ & $\begin{array}{l}\text { - Why is this question important? } \\
\text { - Is this question easy or difficult to answer? } \\
\text { - Why do you think that? } \\
\text { - What assumptions can we make based on this question? } \\
\text { - } \text { questions? }\end{array}$ \\
\hline - $\quad$ Assumption questions & $\begin{array}{l}\text { - Why would someone make this assumption? } \\
\text { - What is } \quad \text { assuming here? } \\
\text { - You could we assume instead? } \\
\text { - } \quad \text { Do I understand you correctly? } \\
\end{array}$ \\
\hline - $\quad$ Reason and evidence questions & $\begin{array}{l}\text { - What would be an example? } \\
\text { - Why do you think this is true? } \\
\text { - What other information do we need? } \\
\text { - Could you explain your reason to us? } \\
\text { - } \quad \text { Is there reason to doubt that evidence? } \\
\text { - What led you to that belief? }\end{array}$ \\
\hline - $\quad$ Origin or source questions & $\begin{array}{l}\text { - Is this your idea or did you hear if from someplace else? } \\
\text { - Have you always felt this way? } \\
\text { - Has your opinion been influenced by something or someone? } \\
\text { - Where did you get that idea? } \\
\text { - What caused you to feel that way? }\end{array}$ \\
\hline $\begin{array}{l}\text { - Implication and consequence } \\
\text { questions }\end{array}$ & $\begin{array}{l}\text { - What effect would that have? } \\
\text { - Could that really happen or probably happen? } \\
\text { - What is an alternative? } \\
\text { - What are you implying by that? } \\
\text { - If that happened, what else would happen as a result? Why? }\end{array}$ \\
\hline - Viewpoint questions & $\begin{array}{l}\text { - How would other groups of people respond this question? } \\
\text { - Hhy? } \\
\text { - Wow could you answer the objection that } \\
\text { - What is an alternative? } \\
\text { - How are ___ and __ ideald make? }\end{array}$ \\
\hline
\end{tabular}

Some of my most employed Socratic question types are questions about an initial issue, clarification questions, reason and evidence questions, origin/source questions, and viewpoint questions. Within my discussion forums, this kind of querying has promoted peer-interaction as well as independent thinking and strives to encourage student ownership of the learning process (Intel, 2007). 


\section{Figure 4}

\section{Socratic Questioning Within Discussion Forum}

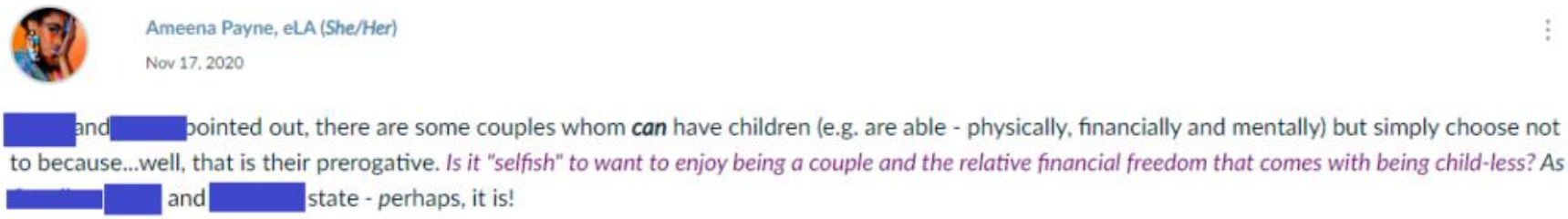

When we are told that we are "selfish," there is an automatic feeling that we are doing something shameful. But selfishness doesn't have to be a bad thing. Should we be embracing this and not apologizing for putting ourselves first in this regard? What do you think?

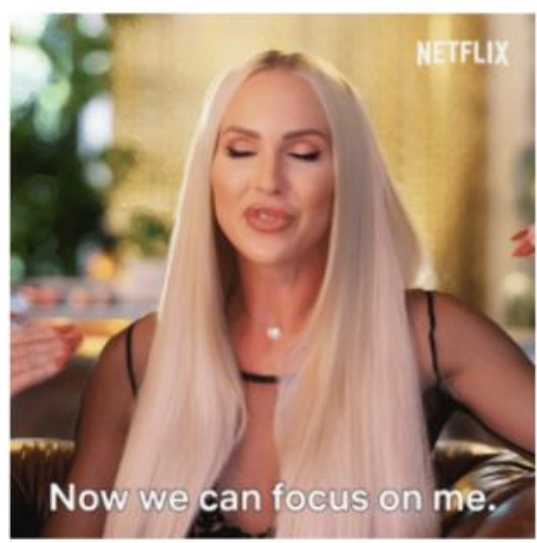

Online instructors should shift away from domineered "telling". Instead, discussion forums should aim to empower and provide opportunities for students to engage in two-way learning conversations and become co-creators of knowledge. ${ }^{1}$

\section{Strategy \#4 Reframes}

It is the role of the unit facilitator to guide students in discussions involving effective summarising of formative and/or summative activities (Salmon, 2011). I plan out meaningful reframes (introductory posts) each week that guide the student through the formative activity. Reframes serve to motivate students to connect with the discussion activity.

Reframes aim to reproduce the material in a shortened form, picking out the main points and posing a discussable prompt (Salmon, 2011). The below discussion activity asked students to watch a video and read prescribed literature regarding the key topic of modern relationships in Australian society. Students were then requested to post their perspective, backed up with scholarly evidence, on whether dating applications were of benefit or detriment to relationships. One aim was for students to be able to actively explore the topic and provide a range of potentially divergent but informed viewpoints from several different perspectives.

\footnotetext{
${ }^{1}$ Described by Associate Professor Rola Ajjawi at the Surrey International Symposium: Feedback Literacy: From education to professional practice (2021) https://blogs.deakin.edu.au/cradle/2021/02/18/feedback-literacy-from-education-to-professional-practice/
} 


\section{Figure 5}

\section{Reframe Example}

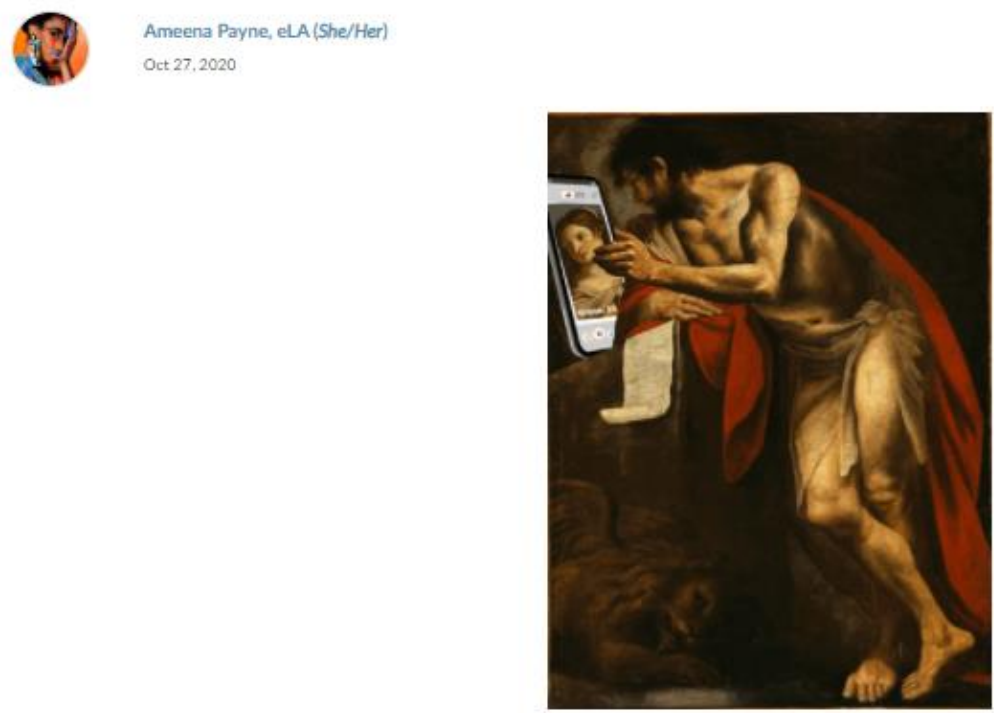

This is our last discussion before a well-deserved Consolidation week and holiday break.

This week we look at essay topic 4: family and relationships and the impact of technology on dating. Dating apps have had an increasingly larger influence on intimate relationships - particularly during COVID lockdowns $\mathrm{a}^{\mathrm{a}}$ where face-to-face outings were not always possible.

On the one hand the convenience and range of choice may have a detrimental impact on how we may choose a partner (if at all). On the other hand, dating apps are providing increased dating opportunities for various demographics such as older people, LGBTQI+, those with varied abilities and those leading busy lives.

As we discovered in the work/life balance topic, technology has meant that people are busy, and finding a partner in the "traditional" way may be difficult; a dating app provides an opportunity to meet a like-minded partner. The challenge is to find a partner that you can build a relationship founded on trust, respect and friendship. What do you think?

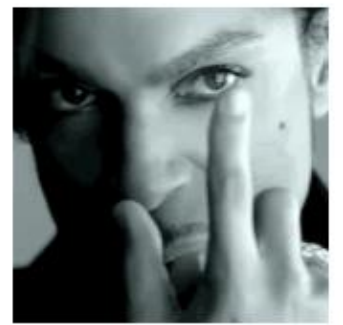

\section{Strategy \#5 Weaving}

A weave is a discussion board post which acknowledges student contributions and earlier discourses (mentioning students by name), expanding upon the conversation through Socratic questioning and prompting students to engage with their peers to deepen learning and establish a sense of community. "Weaves seek opportunities to add value to participants contributions" (Salmon, 2011, p. 207). Where appropriate, weaves can and should incorporate relevant and/or witty multi-media such as GIFs, memes or other images, audio or video. 


\section{Figure 6}

Weaving Example

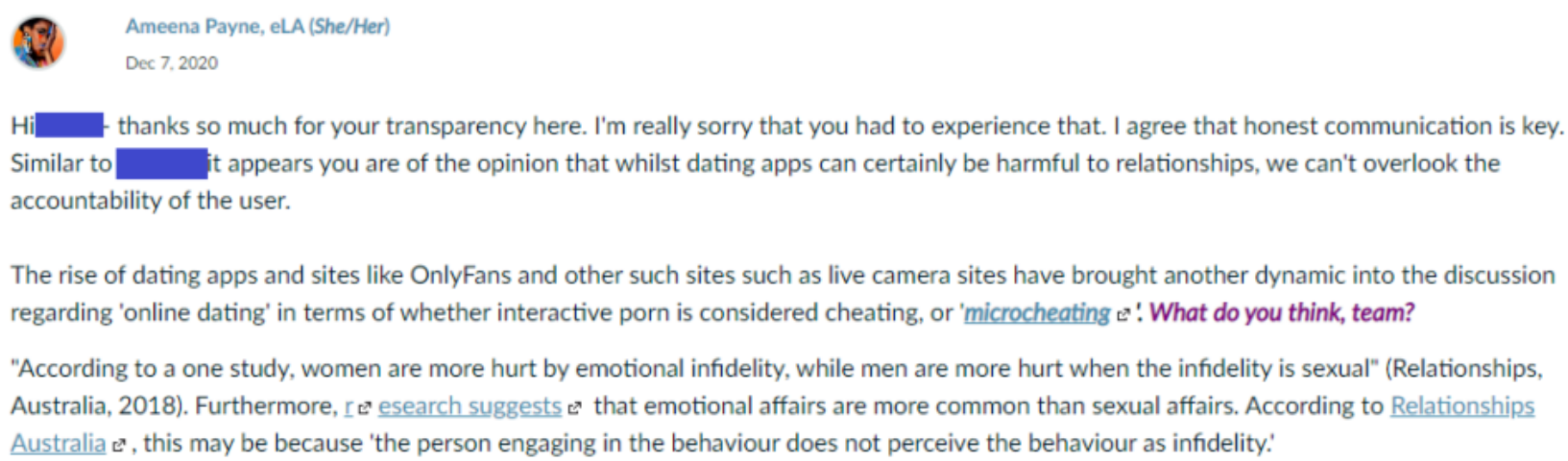

It is vital to be responsive and adaptable to students. Dewey (1997) advocated for empowering students by honouring their experiences. It is equally important to maintain a strong visual presence on the forums. E-moderators should strive to provide group and individual responses where appropriate. We should demonstrate a continuous stream of communication and provide timely and detailed responses (Jarvenpaa et al., 1998). In my experience I believe that e-moderators should aim to post in their discussion forums at least every 48 hours (even if there is little active engagement).

Online educators should establish the kinds of dynamic and supportive discussion forums that are unsupported through didactic and pedantic instruction. The creation of engaging, high trust spaces that are rich with optimism, excitement, interactivity, continuous streams of communication, rapid and thorough responses, and two-way dialogue facilitate and enrich the learning process.

The student discussion board learning experience should encourage participation and connections - both between experiences, content and with peers. Our aim is to offer the opportunity of continuous discussion through the CoI framework. Ultimately, we want to have students who are engaged and supported in their learning, leading to successful outcomes in their chosen units. This aims to feed into student retention, advancement and ultimately successful completion of a tertiary qualification.

\section{Acknowledgement}

I would like to acknowledge the Wurundjeri People of the Kulin Nation, as the traditional owners of the lands in which I live. I express my gratitude to the Wurundjeri People for their guardianship of this land, for which I have benefited. I pay my respects to all elders of the Kulin Nation, past, present and emerging.

Whilst I am engaging in contemporary knowledge, teaching and learning, I would also like to pay my respect to the knowledge embedded forever within Indigenous ways of knowing, and Aboriginal Custodianship of Country. 


\section{References}

Anderson, T., Rourke, L., Garrison, D. R., Archer, W. (2001). Assessing teaching presence in a computer conference environment. Journal of Asynchronous Learning Networks, 5(2), 1-17. http://dx.doi.org/10.24059/olj.v5i2.1875

Boettcher, J. (2007). eCoaching tip 51: A garden of three presences - Social presence, teaching presence and cognitive presence. Designing for Learning. http://designingforlearning.info/ecoachingtips/ecoaching-tip-51/

Department of Education, Skills and Employment. (2020). Higher Education Statistics: 2019 Section 1 Commencing students. https://www.dese.gov.au/higher-education-statistics/resources/2019-section-1-commencing-students

Dewey, J. (1997). Experience and education. Simon \& Schuster Inc.

Garrison, D. R., Anderson, T., \& Archer, W. (2001). Critical thinking, cognitive presence, and computer conferencing in distance education. American Journal of Distance Education, 15(1), 7-23. https://doi.org/10.1080/08923640109527071

Intel. (2007). The Socratic questioning technique. Intel Teach Program: https://www.intel.com.au/content/dam/www/program/education/us/en/documents/project-design/strategies/dep-questionsocratic.pdf

Jarvenpaa, S. L., Knoll, K., \& Leidner, D. E. (1998). Is anybody out there? Antecedents of trust in global virtual teams. Journal of Management Information Systems, 14(4), 29-64. https://doi.org/10.1080/07421222.1998.11518185

Payne, A. L. (2021). Technology-enhanced feedback in higher education: Source-recipient relationships in a new dialogic paradigm. EdArXiv 1-16. https://doi.org/10.35542/osf.io/9ehgb

Pundt, A., \& Herrmann, F. (2015). Affiliative and aggressive humour in leadership and their relationship to leader-member exchange. Journal of Occupational and Organizational Psychology, 88, 108-125. https://doi.org/10.1111/joop.12081

Rourke, L., Anderson, T., Garrison, D. R., \& Archer, W. (2001). Assessing social presence in asynchronous, text-based computer conferencing. Journal of Distance Education, 14(3), 51-70.

Salmon, G. (2011). E-Moderating: The key to online teaching and learning (3rd ed.) Routledge.

The Social Research Centre. (2020). 2019 SES national report. The Social Research Centre. https://www.qilt.edu.au/qiltsurveys/student-experience

Vaughan, N., \& Garrison, R. (2006). A blended faculty community of inquiry: Linking leadership, course redesign, and evaluation. Canadian Journal of University Continuing Education, 32(2), 67-92.

\section{Please cite this article as:}

Payne A.L. (2021). A resource for e-moderators on fostering participatory engagement within discussion boards for online students in higher education. A practice report. Student Success, 12(1), 93-101. https://doi.org/10.5204/ssj.1865

This practice report has been accepted for publication in Student Success. Please see the Editorial Policies under the 'About' section of the Journal website for further information. 